\title{
Study on the Necessity and Contents of Socialized Services of University Libraries
}

\author{
Xiuqi Gong \\ University of Shanghai for Science and Technology Library, Shanghai, China \\ Email address: \\ 2509845424@qq.com \\ To cite this article: \\ Xiuqi Gong. Study on the Necessity and Contents of Socialized Services of University Libraries. Science Journal of Education . \\ Vol. 5, No. 5, 2017, pp. 232-235. doi: 10.11648/j.sjedu.20170505.19
}

Received: June 1, 2017; Accepted: June 28, 2017; Published: November 21, 2017

\begin{abstract}
In recent years, the opening up of university libraries has always been the focus of the library field. This paper describes the necessity of breaking down the walls for the university libraries to provide services for the society relying on resources, talents, technology and other advantages under the premise of ensuring the information needs of the teachers and students, and discusses the detailed service contents and the existing problems in practice, so as to provide advices to further promote socialized services of university libraries.
\end{abstract}

Keywords: University Libraries, Socialized Services, Necessity, Content

\section{Introduction}

"The library should not serve only a particular class and should be open to anyone willing to come to the library," said Gabriel Naude, a famous French librarian [1]. As a part of the library system, the university library can not only be limited to serve the teachers and students of the university, but also it should become a broader platform to accept the readers of the society, provide services for the society and make contributions to the spiritual civilization construction of the whole society [2].

In recent years, the demand for the opening of the university library to the society has been increasing. The university libraries in some of the developed countries have carried out the socialized services for many years, and reached a high level [3]. The opening of the university library is not only a need for its sustainable development, but also a way of fulfilling social responsibility [4].

\section{Necessity of Socialized Services of the University Library}

\subsection{Demand of the Nationwide Reading Era}

United Nations Educational, Scientific, and Cultural Organization (UNESCO) firstly put forward the concept of
"Nationwide Reading" in 1972, and determined the day of April 23, 1995 as the "World book and Copyright Day" in order to promote the development of the nationwide reading worldwide [5]. The nationwide reading has now been universally accepted by the countries all over the world and has become an important measure in improving the national strength.

The university library as the soul of the university has an absolute advantage and value in improving literacy and promoting nationwide reading. The university library has a wealth of physical collections and e-books, foreign language database and other virtual collections, which has a unique advantage especially in academic materials, research-level disciplines collection, and provide the good conditions for the nationwide reading. Universities absorb and cultivate the high-quality and professional talents in different fields. The high-quality and professional librarian team makes that the university library has the advantage of talents to carry out the nationwide reading. Meanwhile, the university library is located in the beautiful university campus with a thick scholar atmosphere and deep cultural heritage. Most of the readers of the university library are the teachers and students with high quality and strong curiosity. It shapes the unique culture and learning atmosphere of the university library.

Therefore, the university library is more likely to stimulate the reader's reading interest, and cultivate the reader's good reading habits. In the environment of nationwide reading, 
university libraries should serve for the society and make contribution to the nationwide reading.

\subsection{Socialization Trend of Resource Sharing}

In today's fast-growing information age, social readers have universal needs for the information. The library as an important cultural position of society, is one of the main places for the readers to obtain information. However, inadequate numbers and unbalanced development of the public libraries in some areas lead that the limited public cultural service resources cannot meet the increasing spiritual and cultural needs of the people [6]. The university library is not only the center of campus culture, but also the social education and learning center. It should extend its socialized services and promote their collection of resources to the people, so that books and knowledge can flow, which will enhance public cultural quality and make up the shortage of public libraries.

University libraries in some of the western countries have already become important helpers for public learning, research and life relying on advanced equipment, rich resources and professional services [7]. It is the inevitable trend and requirements of social development that the university libraries gradually open to the public.

\subsection{Expansion of the University Influence and Promotion of Economic Development}

Opening to the community of the local university libraries is not simply to fulfill their social responsibilities and obligations, universities can also benefit from it. Firstly, when the university library provides information services and communicate with the community, more people have a better understanding of universities. It can change the university image of the "Ivory Tower", increase the visibility of the university and improve the status and impact of the university. Secondly, librarians can strengthen the sense of service, competition and participation, and further improve their services after understanding the social needs, grasping the pulse of the times, and taking the initiative to participate in social services. Thirdly, it can broaden the space of the development of local university library service, play the scientific research ability of the university, assume the important task of the information service construction, and promote the local economic development [8].

\section{Study on the Contents of Socialized Services of University Libraries}

\subsection{Social Public Visit}

The university library building is the landmark in the university campus on behalf of the university culture. The university library can organize social readers to visit so that they feel the campus culture and the library of scholarly atmosphere, so as to improve the cultural quality and literacy.

The library can provide the detailed tour and parking guides on the official website to make it easy for ordinary visitors who are not familiar with the campus. The librarian can assist the visitors to browse the library database, the collection catalogs and other educational resources on the website, and guide the readers to visit the various exhibitions held by the library. At the same time, the library can provide the reference services, printing and scanning and free wireless network for visitors.

\subsection{Library-Lending Services}

The university library can provide the socialized service of the book circulation and the reading, so that the public can make full use of the printed books in the library collection. There is a big gap between the residents' reading requirements and university library resources, that is, university library collection which features on materials for teaching and research is mainly to meet the needs of teaching and research, while residents in different age groups have different reading needs which is more close to the real life. Therefore, the university library must strengthen the collection construction and purchase more literature suitable for the reading needs of the community and the residents, such as fashion news, entertainment, health care etc., so as to meet the borrowing needs of social readers.

Besides allowing the social readers to borrow and read books inside the library, the university library can provide the mobile library services by supplementing the idle books to the community, the institutions or the primary and middle school libraries on the premise that the readers' needs of the university are not affected. The mobile library service should be based on the full investigation of the needs of the readers from both the community and university, and regularly replace books to meet their reading needs.

\subsection{Remote Access to Electronic Resources}

University libraries are rich in physical and electronic resources including e-books, databases, etc. which is an effective channel for readers to obtain scientific research information. Some research institutions and professional technical personnel in the society have higher demands for information services and pay more attention to the convenience and timeliness of the acquired information. They are more interested in electronic resources, especially various categories of the professional database. They have higher professional quality and skills and can independently complete information retrieval. Therefore, the most effective way to serve such readers is to the opening of the remote access to electronic resources, and timely pushing the latest professional information to them.

\subsection{Reading Guidance}

Reading Guidance means that the librarian guide readers how to read books according to the readers' own characteristics and specific needs, and timely solve the problems encountered during reading, and provide them the relevant bibliography [9]. Reading guidance is one of the key points in the library services. The university library should 
carry out the reading guidance service for the social readers to help them improve the reading level and obtain the deeper reading experience.

Most social readers think that the library is only the place to borrow and read books. The library should organize related publicity and training which can help social readers understand the meaning and role of the reading guidance.

Social readers come to the library with different purposes, such as leisure and entertainment, increasing their knowledge or job demands. Readers at different knowledge levels have different reading requirements. The university library should carry out the reading guidance at different levels based on the fully understanding of the residents' reading motivation and acceptability.

The utilization rate of electronic documents increases year by year with the development of network technology. The university library should strengthen the reading guidance service of network information resources and improve the readers' ability of retrieval, screening, processing, and sorting out the information so that readers can quickly and accurately find the necessary information from the complex network of information.

\subsection{References Services}

Reference service refers to the information service mode which guides the users to retrieve the required information or to provide relevant data, document clues, thematic content, etc. to them, based on various kinds of authoritative information sources [10].

University libraries should assign the librarians with good information access and communication skills to provide the service of the reference consultants for social readers.

The university library should help the readers understand the library resources and services through the lectures or user manuals, such as how to use the Online Public Access Catalog (OPAC) to search bibliographic records, and how to borrow, renew, make an appointment, etc. For the readers with higher information needs, librarian can use one-to-one coaching or training classes to guide them to use the tools of databases and search engines to find information. Social readers are encouraged to submit deep level requests through on-site, telephone or network, such as information verification and document information development, etc.

In view of the facts that the problems from social readers may be different from those of the campus' teaching and research readers, it may be more appropriate for them to adopt non-real-time consultation, that is, the reference librarian give answers to the consultation submitted by the users after investigation.

\subsection{Reading Promotion Activities}

The university library should fully carry out the reading promotion activities for the public, strengthen the cooperation between university libraries and social institutions, and speed up the development of the nationwide reading.

University libraries can hold various kinds of reading promotion activities according to the readers' interests and needs of different classes, backgrounds and ages. The library can provide literature courses, introductory technology lectures based on the professional characteristics of the university and the readers' needs, and hold all kinds of activities close to the residents' real life in the community, such as fitness, cooking, weaving, painting and calligraphy exhibition, arts and crafts exhibition. It can strengthen the communication between the library and the community, stimulate the readers' interest in reading and ultimately achieve the purpose of promoting readers' active reading.

University libraries should cooperate with institutions to promote the development of nationwide reading together. Libraries can attract institutional enthusiasts to act as liaisons for reading activities, and regularly organize their members to read after work and study, or the librarians organize the staff or students to set up the reading clubs to regularly read and discuss the related topics.

Librarians can organize some lively reading activities in places like shopping centers, schools, leisure centers and so on, and increase publicity effect, so that the nationwide reading activities can have an effect on everyone in the society as much as possible.

\section{Problems in the Socialized Service of University Library}

Although the socialized services of university libraries have been mentioned for a long time and well implemented in some universities, there are still some problems in the implementation. (1) The orientation of the university library and the social public awareness of its service only in the universities have posed an obstacle to expand its ability of social services. (2) Because the enthusiasm of the university library to carry out the socialized service is not high, and the external publicity is insufficient, the atmosphere and consciousness for social readers of using the university library have not been formed. (3) The university library lacks the adequate understanding for the demand of the social readers. (4) Tense spaces in the campus and library and security risks are caused by a large number of social readers. (5) There is a contradiction between the intellectual property protection and the resource sharing. (6) The increase in circulation may lead to the damage to books.

\section{Conclusion}

The development of the society and the information demand of the public put forward the socialized service requests to the university library. The university library should fully recognize the importance of this change for themselves and the development of the society, and actively provide service to the society to promoting information progress of the society. At the same time, university libraries should strengthen the study and take effective measures to solve various problems encountered in the practice so as to provide better service. 


\section{References}

[1] Liqin Zeng. Analysis of Public Libraries' Zero-threshold--Taking Guangzhou Library as An Example. Shanxi Library Journal, No. 2, 2016, pp. 51-69.

[2] Shuya Yang, Chunyu Zhang, Qingchao Meng. Socialized Service Model of University Libraries in Hebei. Inner Mongolia Science Technology \& Economy, No. 3, 2016, pp. 149-153.

[3] Ying Gao. Connotation and Enlightenment of Service Socialization in Foreign University Libraries. Library, No. 3, 2016, pp. 85-89.

[4] Yongzhong Lai. On Socialized Service of the Library of Colleges and Universities. Journal of Guizhou Normal University (Social Science), No. 4, 2016, pp. 139-144.

[5] Dongping Hou. Study on Socialized Services of University Library under Nationalwide Reading View. Inner Mongolia Science Technology \& Economy, No. 17, 2015, pp. 125-128.
[6] Jialian Wang. Trouble and Method of Library in View of Informatization. The Library Journal of Henan, No. 2, 2014, pp. $100-102$.

[7] Hongqi Cai. A comparative Study on Opening up University Libraries between China and Other Countries. Journal of Guangzhou Open University, No. 3, 2016, pp. 102-105, 112.

[8] Fang Yang, Xin Feng. Research and Practice of Socialized Service Mode of Local University Libraries in the Era of "Internet +": Taking the Library of Hunan Medical College as an Example. Jiangsu Science \& Technology Information, No. 2 , 2017, pp. 19-20, 37.

[9] Yan Peng. Considerations about Public Library's Reading Guidance. Journal of Library and Information Science, No. 8, 2016, pp. 66-68.

[10] Juan Jia. Investigation and Survey on Northwester Academic Libraries' References Services under the Specifications for Library References Services. Journal of the National Library of China, No. 1, 2017, pp. 23-28. 